\title{
Blood eosinophils as a marker of response to inhaled corticosteroids in COPD
}

\author{
Neil C. Barnes ${ }^{1,2}$, Raj Sharma ${ }^{1}$, Sally Lettis ${ }^{3}$ and Peter M.A. Calverley ${ }^{4}$ \\ Affiliations: \\ ${ }^{1}$ Respiratory Medical Franchise, GSK, Brentford, UK. \\ ${ }^{2}$ William Harvey Research Institute, Barts and The London School of Medicine and Dentistry, London, UK. \\ ${ }^{3}$ Clinical Statistics and Programming, GSK, Uxbridge, UK. \\ ${ }^{4}$ Respiratory Research Dept, University of Liverpool, Liverpool, UK.
}

\section{Correspondence:}

Neil Barnes, GSK, 980 Great West Road, Brentford TW8 9GS, UK.

E-mail: neil.c.barnes@agsk.com

ABSTRACT Identification of a biomarker that predicts response to inhaled corticosteroids (ICS) would help evaluate the risk/benefit profile of ICS in chronic obstructive pulmonary disease (COPD) and guide treatment.

The ISOLDE study randomised 751 patients (mean post-bronchodilator forced expiratory volume in $1 \mathrm{~s}$ (FEV1) $1.4 \mathrm{~L}: 50 \%$ predicted normal) to fluticasone propionate $500 \mu \mathrm{g}$ twice daily or placebo for 3 years, finding no difference in FEV1 rate of decline between treatments $(p=0.16)$ and a significant reduction in median exacerbation rate with fluticasone propionate versus placebo $(\mathrm{p}=0.026)$. We re-analysed ISOLDE results by baseline blood eosinophil count to investigate whether eosinophil level predicts ICS benefit.

Patients with eosinophils $<2 \%(n=456)$ had a similar rate of post-bronchodilator FEV1 decline with fluticasone propionate as placebo $\left(-2.9 \mathrm{~mL} \cdot \mathrm{year}^{-1} ; \mathrm{p}=0.688\right)$. With eosinophils $\geqslant 2 \%(\mathrm{n}=214)$, the rate of decline decreased by $33.9 \mathrm{~mL} \cdot \mathrm{year}^{-1}$ with fluticasone propionate versus placebo $(\mathrm{p}=0.003)$. Exacerbation rate reduction on ICS for fluticasone propionate versus placebo was higher in the eosinophil $<2 \%$ group compared with the $\geqslant 2 \%$ group; time-to-first moderate/severe exacerbation was not different between treatments in either group.

A baseline blood eosinophil count of $\geqslant 2 \%$ identifies a group of COPD patients with slower rates of decline in FEV1 when treated with ICS: prospective testing of this hypothesis is now warranted.

@ERSpublications

Blood eosinophil level identifies COPD patients showing a slower rate of lung function decline when treated with ICS http://ow.ly/X6HyJ

Editorial comment in: Eur Respir J 2016; 47: 1299-1303.

This article has supplementary material available from erj.ersjournals.com

Received: Aug 182015 | Accepted after revision: Jan 102016 | First published online: Feb 252016

Support statement: The ISOLDE study and the current pre-specified analysis of ISOLDE were sponsored by GSK. Funding information for this article has been deposited with FundRef. Employees of the sponsor had roles in the design and conduct of the study and in the analysis and interpretation of the data. All authors, including employees of the sponsor, participated in the development of the manuscript and had access to the data from the study. The decision to submit for publication was that of the authors alone; GSK did not place any restrictions on access to the data or on the statements made in the manuscript.

Conflict of interest: Disclosures can be found alongside the online version of this article at erj.ersjournals.com

Copyright CERS 2016 


\section{Introduction}

Chronic obstructive pulmonary disease (COPD) is characterised by persistent airflow limitation and, although treatable, it is usually progressive $[1,2]$. Treatment with inhaled corticosteroids (ICS) and a long-acting $\beta_{2}$-agonist (LABA) bronchodilator improves lung function and quality of life, and reduces the frequency of exacerbations in patients with moderate/severe COPD [1, 3-5]. However, ICS-containing regimens are associated with an increased risk of pneumonia in COPD patients [6-8]. The identification of a biomarker that could help predict response to ICS would help to evaluate the risk/benefit ratio of ICS in COPD patients and assist clinicians with treatment selection.

Fluticasone propionate is a twice-daily ICS used as maintenance therapy for COPD, in combination with a LABA bronchodilator [1]. Fluticasone propionate monotherapy was compared with placebo in the 3-year ISOLDE study, a double-blind, placebo-controlled trial which tested the effect of ICS on disease progression in moderate/severe COPD [9]. No difference was seen in the rate of decline $\left(\mathrm{mL} \cdot y e a r^{-1}\right)$ of post-bronchodilator forced expiratory volume in $1 \mathrm{~s}$ ( FEV1) for fluticasone propionate versus placebo (primary end-point: $\mathrm{p}=0.16$ ) but there was a significant reduction in the secondary end-point of median yearly exacerbation rate with fluticasone propionate versus placebo (0.99 versus 1.32 year $^{-1}$, respectively; reduction of $25 \% ; \mathrm{p}=0.026$ ). However, withdrawal rates were high in ISOLDE during both the 8 -week run-in ( $24 \%$ of eligible patients) and double-blind treatment ( $43 \%$ fluticasone propionate; $53 \%$ placebo).

Two small studies suggested the risk of severe COPD exacerbations is reduced when corticosteroid treatment is titrated to normalise sputum eosinophil count $[10,11]$. A high sputum eosinophil count has been associated with an FEV1 response to systemic corticosteroids [12, 13], but sputum eosinophil assessments are technically more difficult to perform than analysis of blood eosinophils and are not always successful [14]. Therefore, assessing levels of blood eosinophil numbers may be a practical alternative to sputum assessments. There is an association between blood and sputum eosinophil counts in COPD, with a differential count of $\geqslant 2 \%$ of the total white blood cell count having a positive predictive value of $90 \%$ for raised induced sputum eosinophils [14]. Blood eosinophil count $\geqslant 2 \%$ is associated with increased risk of moderate/severe exacerbations [15-17], and patients with a high eosinophil count and asthma have an increased mortality due to COPD in later life [18]. However, the relationship between eosinophils and decline in lung function (FEV1) in patients receiving ICS has not been reported.

We hypothesised that baseline blood eosinophil count would be related to rate of lung function decline and that this would be slower if patients with a higher baseline eosinophil count were treated with an ICS. To test these ideas we undertook a retrospective analysis of data from the ISOLDE study, using a blood eosinophil cut-off of $<2 \%$ versus $\geqslant 2 \%$ to categorise patients.

\section{Materials and methods}

Overview of ISOLDE study

The ISOLDE study design has been described previously [9]. Eligible patients were aged 40-75 years, current or previous smokers with moderate/severe COPD and post-bronchodilator FEV1 $\geqslant 0.8 \mathrm{~L}$, but $\leqslant 85 \%$ of predicted normal. Patients taking ICS and/or oral corticosteroids had to have stopped these treatments before entry to the 8 -week run-in period. During the study, LABAs were permitted. However, the study pre-dated the wide use of long-acting inhaled bronchodilators, with only $6 \%$ of patients in the placebo and fluticasone propionate treatment group continuing salmeterol into the randomised treatment period and none taking tiotriopium; a further $2 \%$ and $1 \%$ patients, respectively, stopped salmeterol prior to the treatment period.

Patients were excluded if their FEV1 response to salbutamol $400 \mu$ g exceeded $10 \%$ of predicted normal, they had a life expectancy of $<5$ years from comorbid conditions or if they used $\beta$-blockers. The protocol was approved by each centre's local ethical committee and patients provided written informed consent. Eligible patients entered an 8-week run-in and were then randomised to either fluticasone propionate $500 \mu \mathrm{g}$ twice daily or placebo twice daily. Baseline eosinophil count was taken as the last value obtained prior to initiating study treatment (online supplementary table S1). Most patients (if they agreed and were not contraindicated) had an open 2-week oral prednisone trial $\left(0.6 \mathrm{mg} \cdot \mathrm{kg}^{-1} \cdot \mathrm{day}^{-1}\right)$ before starting treatment in the double-blind phase. All patients were given salbutamol $200 \mu \mathrm{g}$ and ipratropium bromide $80 \mu \mathrm{g}$ as symptomatic relief. During the 3-year double-blind phase, patients visited a clinic every 3 months for spirometry, recording of exacerbations and safety assessments.

The primary end-point was the decline $\left(\mathrm{mL} \cdot \mathrm{year}^{-1}\right)$ in $\mathrm{FEV}_{1}$ after bronchodilator using data from 3-36 months (baseline was included as a covariate and was the mean of measurements taken at weeks 4 and 8 of the run-in, pre-prednisone). Secondary end-points included exacerbation rate (defined by treatment use and/or hospitalisation), change in health status, withdrawals due to respiratory disease and adverse events. This study was performed before the registration of clinical trial data was introduced. 
Analysis of ISOLDE data according to eosinophil levels

This was a retrospective analysis of data from patients in the primary analysis of ISOLDE. Blood eosinophil levels were measured at screening, at the end of the 8-week run-in, after each year of study treatment and on early withdrawal. In keeping with previous reports [14], patients were categorised according to their last eosinophil count $(\geqslant 2 \%$ or $<2 \%)$ prior to the start of the double-blind treatment period (as stated in the pre-specified analysis plan).

The primary outcome was rate of decline in FEV1 (pre/post-bronchodilator) in each subgroup using data from 3 to 36 months (as in the original ISOLDE analysis). Secondary outcomes were time-to-first and annual rate of moderate and severe exacerbations, pre- and post-bronchodilator FEV1 including weighted mean over the treatment period, effect of ICS on eosinophil count, change from baseline in St George's Respiratory Questionnaire (SGRQ) total scores [19], and adverse events by eosinophil subgroup (including proportion of patients experiencing pneumonia, reported as an adverse event).

The rate of decline in FEV1 over time was analysed using a random coefficients model for each eosinophil subgroup separately, with FEV1 as the response variable. Fixed effects included age, sex, baseline FEV1, treatment group and time. Subject effects were random. The treatment-group-by-time interaction allowed point estimates and $95 \%$ confidence intervals for slope differences between treatments to be generated for the $<2 \%$ and $\geqslant 2 \%$ eosinophils subgroups. Analysis of FEV1 was performed using a mixed models repeated measures (MMRM) methodology. Point estimates and 95\% CIs for the treatment differences in FEV1 were generated for each day according to each eosinophil subgroup. This was a separate analysis of FEV1 which provided an estimate of treatment difference at each clinic visit. Analysis of time-to-first moderate or severe exacerbation was performed using a Cox proportional hazards model, with covariates including treatment group, sex, FEV1 \% predicted at baseline, eosinophil subgroup and treatment by eosinophil interaction. In light of advances in statistical analysis [20], the annual rate of moderate and severe exacerbations was analysed using a generalised linear model assuming a negative binomial distribution, where the response variable was the number of on-treatment moderate and severe exacerbations experienced per subject using the same covariates as time-to-first exacerbation analysis. SGRQ total score analysis was performed using a MMRM methodology, and rate of decline in health status was assessed from 6 months (the first on-treatment time point) using a random coefficients model. Eosinophils were compared between treatment groups at months 12, 24 and 36 by fitting a MMRM model. All analyses were performed in a HARP (Harmonisation of Analysis \& Reporting Program; GlaxoSmithKline, Brentford, UK) environment using SAS version 9.1.3 (SAS, Cary, NC, USA) or later release.

\section{Results}

Patient disposition and baseline characteristics

Complete patient disposition in the ISOLDE study $(n=751)$ has been reported previously [9]. Patients were randomised to fluticasone propionate $(n=376)$ or placebo $(n=375)$; baseline eosinophil counts were available for 370 patients in the fluticasone propionate group and 368 patients in the placebo group (figure 1). The proportion of patients in each eosinophil group was similar between fluticasone propionate and placebo ( $71 \%$ versus $66 \%(<2 \%)$ and $29 \%$ versus $34 \%(\geqslant 2 \%)$, respectively) (figures 1 and 2 ). Median percentage baseline eosinophil count was 1.27 (eosinophils <2\% group: median absolute count $100 \mathrm{~mm}^{-3}$ ) and 3.17 (eosinophils $\geqslant 2 \%$ group: median absolute count $200 \mathrm{~mm}^{-3}$ ). Baseline characteristics were balanced between groups (table 1). Most participants were male, mean age 63.2-64.1 years, with a mean smoking history of 42.7-47.2 pack-years, and 39-51\% were current smokers. No substantial differences were noted between eosinophil subgroups in terms of demographic or baseline characteristics, including spirometry. In both treatment groups $6 \%$ of patients (21/375 placebo, 23/376 fluticasone propionate) who had been receiving a LABA (salmeterol) at randomisation continued this during the treatment period. In addition, 7\% (25/375) of patients receiving placebo and $5 \%(18 / 376)$ of patients receiving fluticasone propionate started LABA treatment during the randomised treatment phase.

\section{FEV1 analysis by eosinophil count}

In the primary outcome analysis, no significant difference was seen in the annual rate of FEV1 decline with fluticasone propionate $\left(50 \mathrm{~mL} \cdot \mathrm{year}^{-1}\right)$ compared with placebo $\left(59 \mathrm{~mL} \cdot \mathrm{year}^{-1}, \mathrm{p}=0.16\right)$; however, mean FEV1 after bronchodilator remained significantly higher throughout the study with fluticasone propionate $(\mathrm{p}<0.001$ versus placebo) [9]. There was also a significant reduction in median exacerbation rate with fluticasone propionate versus placebo $(\mathrm{p}=0.026)$.

When analysed by baseline blood eosinophil threshold, the group with higher eosinophil count had greater treatment efficacy as measured by FEV1 decline. The rate of decline in post-bronchodilator FEV1 $\left(\mathrm{mL} \cdot \mathrm{year}^{-1}\right)$ was significantly slower with fluticasone propionate versus placebo in the $\geqslant 2 \%$ eosinophil group (33.9 $\mathrm{mL} \cdot$ year $^{-1}$ reduction: -40.6 versus $-74.5 \mathrm{~mL} \cdot$ year $^{-1}$; $\mathrm{p}=0.003$ ), but not in the $<2 \%$ eosinophil group ( -54.2 versus $-51.3 \mathrm{~mL} \cdot \mathrm{year}^{-1} ; \mathrm{p}=0.688$ ) (table 2 ). A post hoc analysis of FEV1 decline in those 


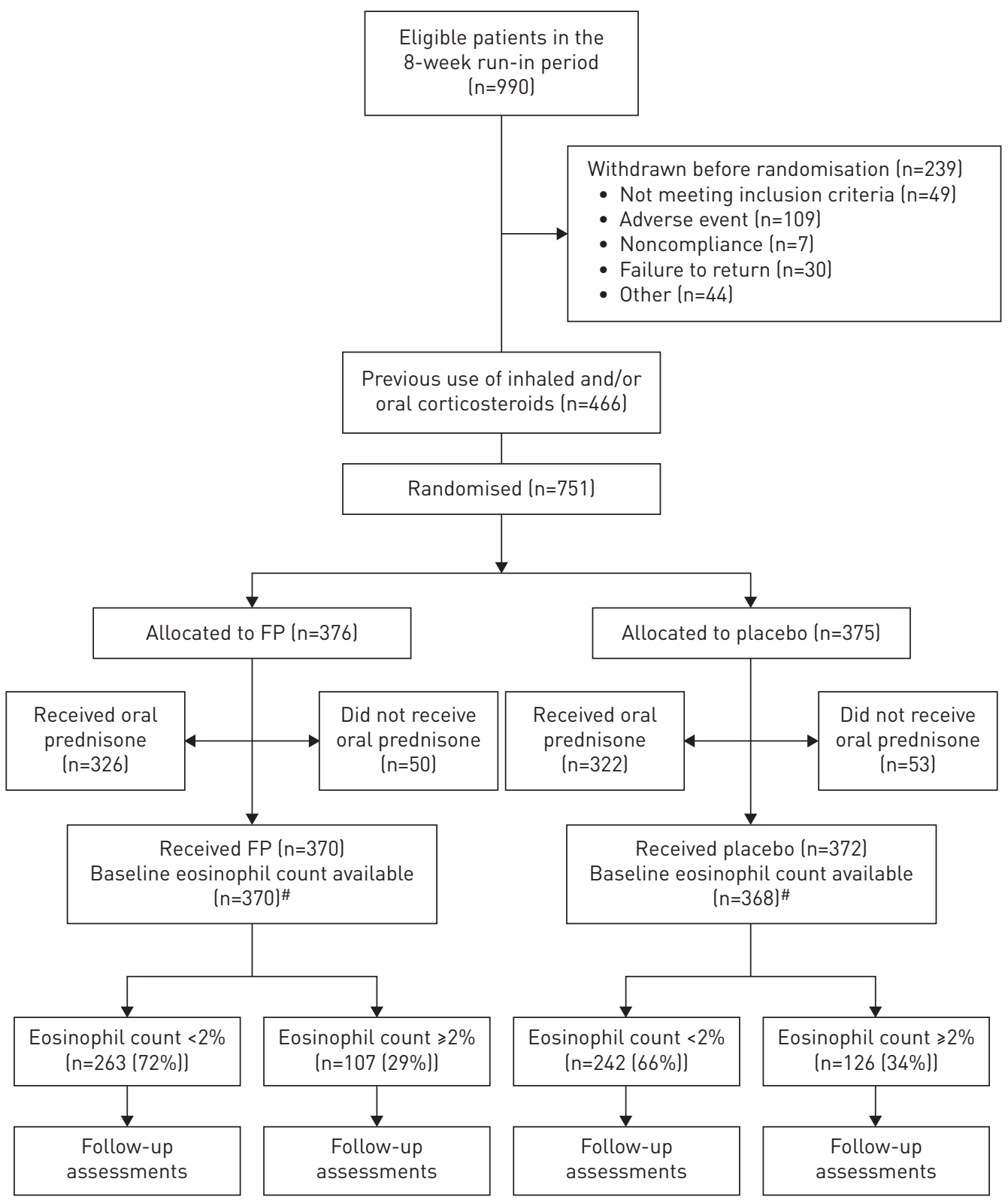

FIGURE 1 Patient flow diagram. Eosinophil measurements were performed at scheduled assessments (screening and before prednisone) or may have been unscheduled. Not all patients received oral prednisone. \#: baseline eosinophil count refers to the last eosinophil count recorded before receiving fluticasone propionate (FP) or placebo.

receiving placebo showed that the difference between the $\geqslant 2 \%$ and $<2 \%$ eosinophil groups was significant ( $\mathrm{p}=0.015)$. Results for pre-bronchodilator FEV1 were similar to post-bronchodilator findings (figure 3). At month 3 , in placebo-treated subjects there was a reduction in post-bronchodilator FEV 1 for $<2 \%$ and $\geqslant 2 \%$ eosinophils ( 43.5 and $30 \mathrm{~mL}$, respectively). For the fluticasone propionate-treated subjects there was a $30 \mathrm{~mL}$ improvement in FEV1 in the $<2 \%$ eosinophil group and a $62.5 \mathrm{~mL}$ improvement in FEV1 in the $\geqslant 2 \%$ eosinophil group.

Using the last eosinophil value prior to inhaled therapy use to define eosinophil category, 43 subjects had the measurement taken while taking, or after stopping, prednisone. Using the last pre-prednisone eosinophil value as baseline made no change to the overall conclusions of the study.

\section{Other efficacy analyses}

No consistent relationship was seen between eosinophil level and relative treatment efficacy in reducing exacerbation rates. Hazard ratios (HRs) for fluticasone propionate versus placebo for time-to-first 


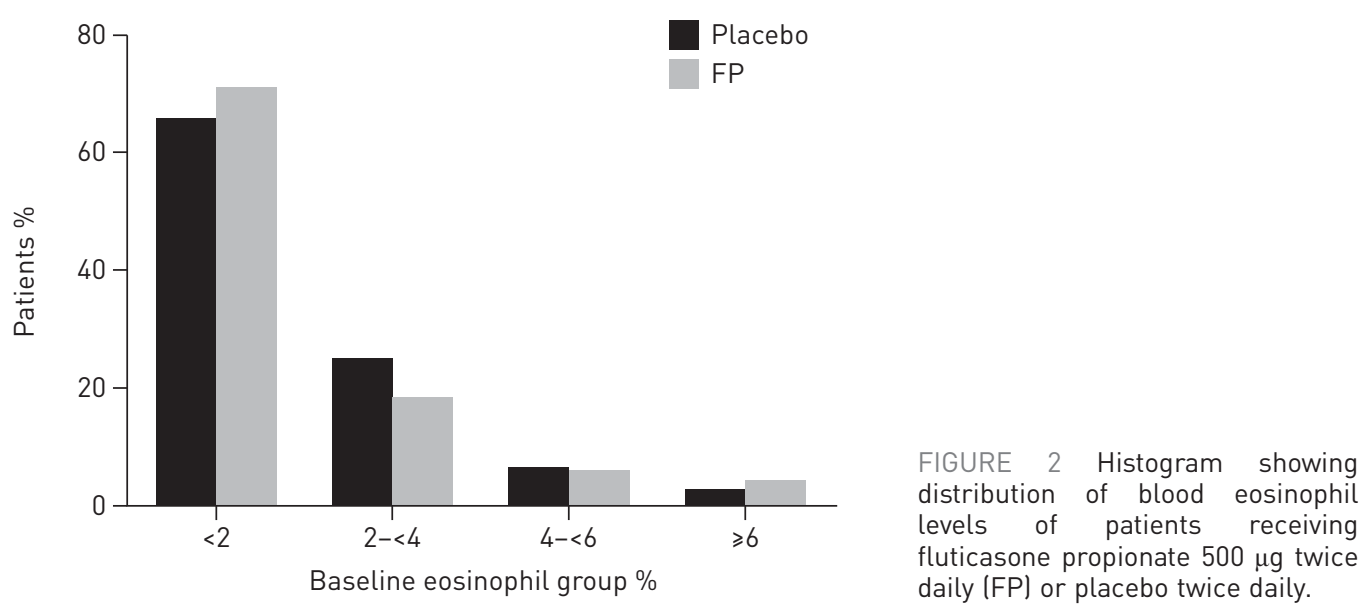

moderate/severe exacerbation were not different between the $<2 \%$ eosinophil group (HR $0.91,95 \%$ CI $0.74-1.11 ; \mathrm{p}=0.330$ ) and the $\geqslant 2 \%$ eosinophil group (HR 1.04, 95\% CI $0.78-1.40 ; \mathrm{p}=0.774$ ). The annual rate of moderate/severe exacerbations (table 3) was significantly lower with fluticasone propionate versus placebo in the $<2 \%$ eosinophil group ( 1.32 versus 1.63 year $\left.^{-1}, \mathrm{p}=0.009\right)$. No significant difference was seen in exacerbation rate among patients receiving fluticasone propionate versus placebo in the $\geqslant 2 \%$ eosinophil group ( 1.59 versus 1.81 year $^{-1}, \mathrm{p}=0.281$ ). The reduction in overall exacerbation rate for fluticasone propionate versus placebo was higher in the $<2 \%$ eosinophil group compared with the $\geqslant 2 \%$ eosinophil group (online supplementary figure S1).

The decrease in health status from baseline was greater for placebo versus fluticasone propionate in both eosinophil groups over 3 years of treatment (table 4: at 36 months 6.83 versus 0.91 in the $\geqslant 2 \%$ eosinophil group, $\mathrm{p}=0.019 ; 9.69$ versus 5.59 in the $<2 \%$ eosinophil group, $\mathrm{p}=0.013$ ), with worsening health status in the $<2 \%$ eosinophil subgroup with both treatments (figure 4 ). There was no significant difference in the rate of decline (assessed using the SGRQ score from 6 months, i.e. the first on-treatment time point) between fluticasone propionate and placebo for either eosinophil subgroup (fluticasone propionate versus placebo: $<2 \%$ : -0.6 year $^{-1}, \mathrm{p}=0.259 ; \geqslant 2 \%:-0.8$ year $\left.^{-1}, \mathrm{p}=0.397\right)$.

\section{Stability of blood eosinophils during the study}

Eosinophil counts at years 1-3 were unaffected by the presence of exacerbations in the 2 months before a visit (online supplementary table S2). The difference in mean percentage change from baseline in blood eosinophil count did not reach significance for the two treatment groups (fluticasone propionate versus placebo) at any time point ( 12 months: $-0.12, \mathrm{p}=0.388 ; 24$ months: $-0.14, \mathrm{p}=0.375 ; 36$ months: $-0.21, \mathrm{p}=0.223$ ).

TABLE 1 Demographics and baseline characteristics of patients receiving fluticasone propionate $500 \mu \mathrm{g}$ twice daily (FP) or placebo twice daily according to blood eosinophil level

\begin{tabular}{|c|c|c|c|c|}
\hline & \multicolumn{2}{|c|}{ Eosinophils $<2 \%$} & \multicolumn{2}{|c|}{ Eosinophils $\geqslant 2 \%$} \\
\hline & FP & Placebo & FP & Placebo \\
\hline Age years & $63.8 \pm 6.94^{\#}$ & $64.1 \pm 6.83^{9}$ & $63.5 \pm 7.34^{+}$ & $63.2 \pm 7.74^{\S}$ \\
\hline Male & $190(72)^{\#}$ & $171(71)^{9}$ & $88(82)^{+}$ & $102(81)^{\S}$ \\
\hline BMI $\mathrm{kg} \cdot \mathrm{m}^{-2}$ & $24.91 \pm 4.92^{\#}$ & $25.17 \pm 4.54^{9}$ & $23.61 \pm 4.28^{+}$ & $24.50 \pm 4.84^{\S}$ \\
\hline White & $260(99)^{\#}$ & 241 (>99) & $106(>99)^{+}$ & $126(100)^{\S}$ \\
\hline Current smoker & $133(51)^{\#}$ & $118(49)^{\pi}$ & $42(39)^{+}$ & $60(48)^{\S}$ \\
\hline Smoking pack-years & $43.2 \pm 29.78^{f}$ & $43.6 \pm 35.58^{\# \#}$ & $47.2 \pm 30.11^{\text {ตाต }}$ & $42.7 \pm 28.65^{++}$ \\
\hline Pre-bronchodilator FEV 1 L & $1.32 \pm 0.472^{\S \S}$ & $1.25 \pm 0.462^{f f}$ & $1.24 \pm 0.444^{\# \# \#}$ & $1.31 \pm 0.496$ ทีก \\
\hline Pre-bronchodilator FEV $1 \%$ pred & $47.3 \pm 15.31^{\S \S}$ & $45.5 \pm 14.90^{f f}$ & $42.5 \pm 14.09^{\# \# \#}$ & $45.4 \pm 15.46$ กาก \\
\hline Post-bronchodilator FEV 1 L & $1.45 \pm 0.485^{\S \S}$ & $1.37 \pm 0.470^{f f}$ & $1.36 \pm 0.440^{\# \# \#}$ & $1.44 \pm 0.496$ ตากา \\
\hline Post-bronchodilator FEV $1 \%$ pred & $51.8 \pm 15.25^{\S \S}$ & $49.9 \pm 14.79 f f$ & $46.5 \pm 13.79^{\# \# \#}$ & 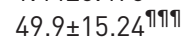 \\
\hline Reversibility to salbutamol $\%$ & $4.5 \pm 3.5^{\S \S}$ & $4.4 \pm 3.35^{f f}$ & $4.1 \pm 3.46^{\# \# \#}$ & 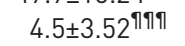 \\
\hline
\end{tabular}

Data are presented as mean \pm SD or $\mathrm{n}(\%)$. BMI: body mass index; FEV1: forced expiratory volume in $1 \mathrm{~s}$; $\%$ pred: \% predicted. Numbers of patients in each analysis group differed depending on data availability. ${ }^{\#}: \mathrm{n}=263 ;{ }^{\uparrow}: \mathrm{n}=242 ;{ }^{+}: \mathrm{n}=107 ;{ }^{\S}: \mathrm{n}=126 ;{ }^{f}: \mathrm{n}=251 ;{ }^{\# \#}: \mathrm{n}=214 ;{ }^{\text {ๆा }}: \mathrm{n}=104 ;{ }^{++}: \mathrm{n}=119 ;{ }^{\S \S}: \mathrm{n}=261 ;{ }^{f f}: \mathrm{n}=240$;

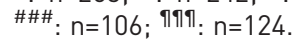


TABLE 2 Rate of decline in post-bronchodilator forced expiratory volume in $1 \mathrm{~s}$ (FEV1) in patients receiving fluticasone propionate $500 \mu \mathrm{g}$ twice daily (FP) or placebo twice daily according to blood eosinophil level ${ }^{\#}$

\begin{tabular}{|c|c|c|c|c|}
\hline & \multicolumn{2}{|c|}{ Eosinophils <2\% } & \multicolumn{2}{|c|}{ Eosinophils $\geqslant 2 \%$} \\
\hline Patients $\mathbf{n}$ & 240 & 216 & 97 & 107 \\
\hline 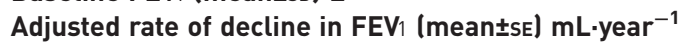 & $-54.2 \pm 4.8$ & $-51.3 \pm 5.3$ & $-40.6 \pm 8.0$ & $-74.5 \pm 8.0$ \\
\hline Slope: FP versus placebo (mean \pm sE) $(95 \% \mathrm{CI})$ & \multicolumn{2}{|c|}{$-2.9 \pm 7.2(-17.0-11.3), p=0.688$} & \multicolumn{2}{|c|}{$33.9 \pm 11.3(11.5-56.2), p=0.003$} \\
\hline
\end{tabular}

Random coefficients model for each eosinophil subgroup separately, with fixed effects of age, sex, baseline post-bronchodilator FEV1, treatment group and time, and random subject effects. "\# : using baseline post-bronchodilator FEV1 as a covariate.

\section{Analysis of adverse events data}

The rate of (and time to) patient withdrawal were unaffected by eosinophil subgroup, with more patients withdrawing when randomised to placebo than fluticasone propionate in both groups (online supplementary table S3 and figure S3).

Adverse event/serious adverse event incidence was comparable when summarised by eosinophil count and treatment group (online supplementary table S4). Compared with placebo, more patients reported pneumonia with fluticasone propionate $(15 / 263(5.7 \%))$ in the $<2 \%$ eosinophil group than for placebo (3/ $242(1.2 \%))$; in patients with eosinophils $\geqslant 2 \%$, the incidence of pneumonia was similar in both treatment groups (5/107 (4.7\%) and 6/126 (4.8\%) for fluticasone propionate and placebo, respectively). Similar findings were seen for serious pneumonia, where $4.6 \%$ and $0.8 \%$ of fluticasone propionate and placebo patients experienced an event in the $<2 \%$ eosinophil group, compared with $3.7 \%$ and $4.8 \%$ in the $\geqslant 2 \%$ eosinophil group. There were seven cases of fatal pneumonia: five in the $<2 \%$ eosinophil group (one placebo, four fluticasone propionate) and two in the $\geqslant 2 \%$ eosinophil group (both placebo). The incidence of on-treatment deaths was similar irrespective of treatment in both eosinophil groups (9\% and 7\% $(<2 \%$ eosinophils) and $7 \%$ and $7 \%$ ( $\geqslant 2 \%$ eosinophils) for placebo and fluticasone propionate, respectively).

\section{Discussion}

One of the major aims of COPD management is to slow disease progression. This has most frequently been studied by trying to reduce the rate of decline of FEV1.

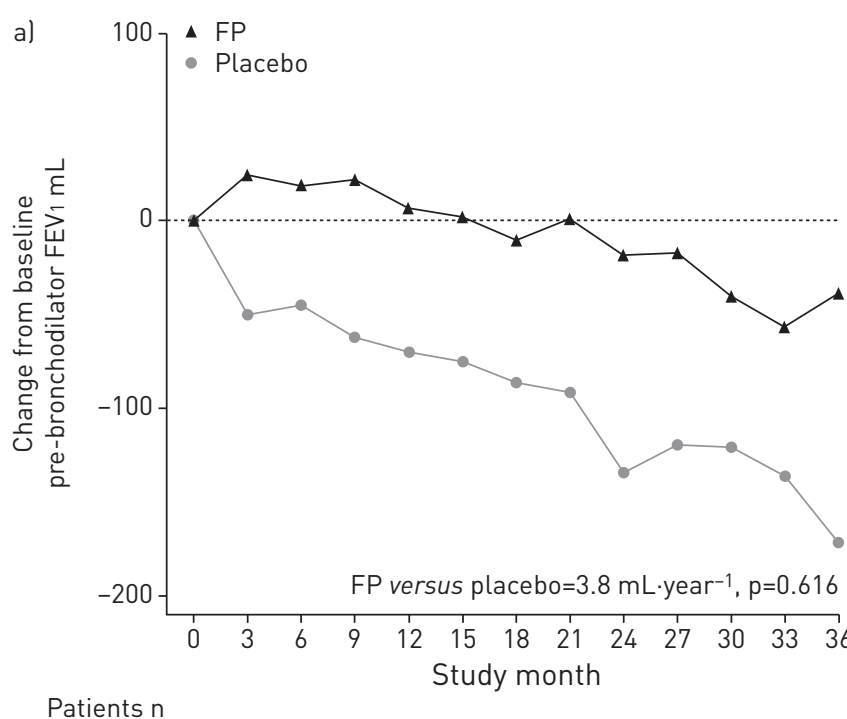

Placebo $89201193169158150147 \quad 138 \quad 127 \quad 126 \quad 116 \quad 10489$ FP 113230208198192178172170165157153149113

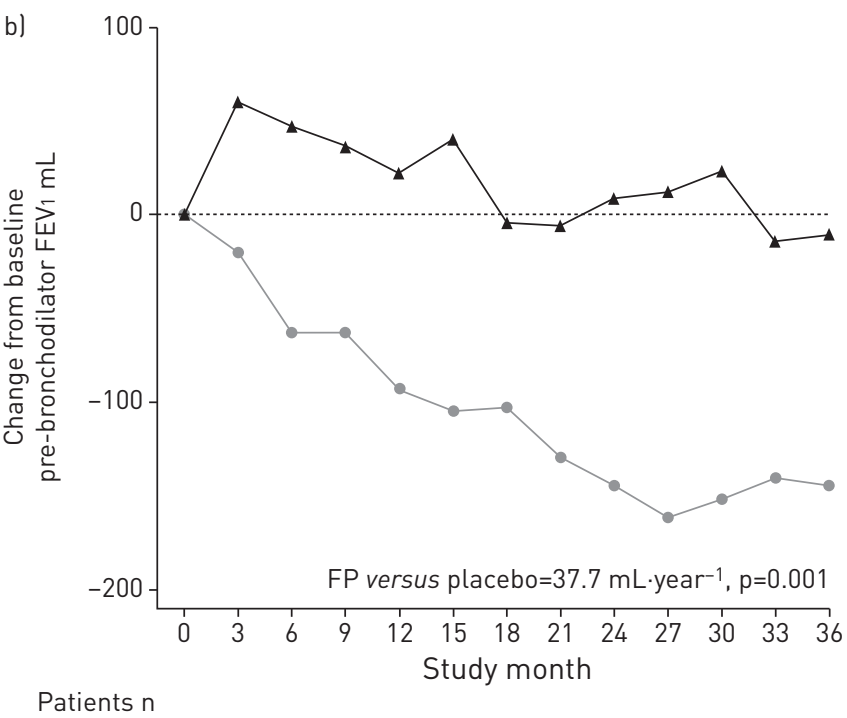

$\begin{array}{llllllllllllll}\text { Placebo } & 48 & 101 & 91 & 90 & 80 & 73 & 71 & 70 & 64 & 65 & 56 & 52 & 48\end{array}$

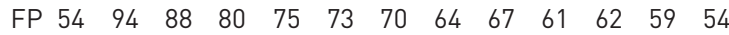

FIGURE 3 Decline in pre-bronchodilator forced expiratory volume in $1 \mathrm{~s}\left(F E V_{1}\right)$ in patients receiving fluticasone propionate $500 \mu \mathrm{g}$ twice daily (FP) or placebo twice daily according to blood eosinophil level: a) $<2 \%$ and $b) \geqslant 2 \%$. Data points represent the adjusted means from the mixed models repeated measures analysis and indicate the change from baseline over time; the slope differences are derived from the random coefficients model. 
TABLE 3 Analysis of moderate/severe exacerbation rates in patients receiving fluticasone propionate $500 \mu \mathrm{g}$ twice daily (FP) or placebo twice daily according to blood eosinophil level (intent-to-treat population)

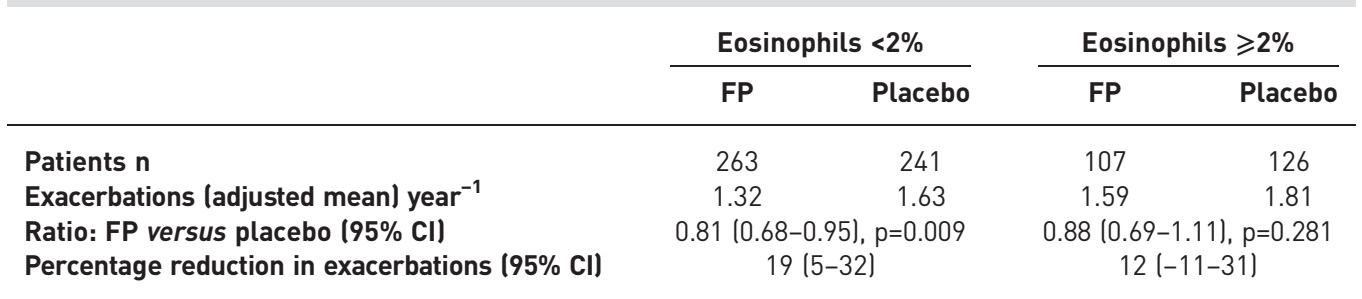

Negative binomial model with covariates of sex and forced expiratory volume in $1 \mathrm{~s} \%$ predicted at baseline.

In this retrospective analysis of data from the 3-year ISOLDE study of fluticasone propionate versus placebo in patients with moderate/severe COPD we found that the rate of annual decline in post-bronchodilator FEV1 was significantly reduced with fluticasone propionate compared with placebo ( $p=0.003$ ) in patients with blood eosinophil levels $\geqslant 2 \%$, but not in the $<2 \%$ eosinophil group. The difference in FEV1 decline between fluticasone propionate and placebo at 3-36 months did not appear to reflect an immediate improvement following 3 months of fluticasone propionate administration in these selected groups of patients.

Several studies have considered the effects of ICS on the rate of FEV1 decline, with contrasting results. As with ISOLDE, they failed to find any significant impact of ICS on FEV1 decline, although in all cases the ICS arm showed the lower rate of change with time [21-23]. An analysis of the TORCH (TOwards a Revolution in COPD Health) study found a statistically significant reduction in FEV1 decline with all active treatments including ICS monotherapy; however, patients were not stratified by their blood eosinophil count [24]. Our data suggest that these earlier findings may reflect differences in the baseline eosinophil count with a preponderance of patients less likely to respond to ICS masking a "true-positive" signal. Regrettably, baseline blood count data are not available in these studies and so this explanation must remain speculative.

The original analysis of exacerbation rates in the overall population of the ISOLDE study showed a reduction over 12 months of fluticasone propionate treatment [9]. In this retrospective analysis, we saw reductions of $12 \%$ and $19 \%$ in the effect of fluticasone propionate on exacerbation rates in the higher and lower eosinophil groups, respectively, with fewer events occurring with treatment in both subgroups. However, reduction was smaller in the higher than lower eosinophil group. This contrasts with large datasets recently reported by PASCOE et al. [16], and from a similar-sized trial of beclomethasone and formoterol [17], although their results reflect addition of ICS to concomitant LABAs, which reduce the exacerbation frequency compared with placebo. Compared with PASCOE et al. [16], the ISOLDE population contained fewer subjects with a higher eosinophil count (32\% versus $66 \%$, respectively) and our patients were not taking LABAs. We noted an increased incidence of exacerbation and hence withdrawal before randomisation among patients who stopped ICS [25], and this could have contributed to the lower overall

TABLE 4 Repeated measures of St George's Respiratory Questionnaire (SGRQ) total score after 3 years of treatment with fluticasone propionate $500 \mu \mathrm{g}$ twice daily (FP) or placebo twice daily according to blood eosinophil level

\begin{tabular}{|c|c|c|c|c|}
\hline & \multicolumn{2}{|c|}{ Eosinophils $<2 \%$} & \multicolumn{2}{|c|}{ Eosinophils $\geqslant 2 \%$} \\
\hline Total patients & 376 & 375 & 376 & 375 \\
\hline $\begin{array}{l}\text { Patients with one or more SGRQ measurements } \\
\text { included in the repeated measures analysis }\end{array}$ & 192 & 172 & 75 & 79 \\
\hline Patients with SGRQ at 3 years & 122 & 98 & 48 & 46 \\
\hline SGRQ total score & $54.59 \pm 1.105$ & $58.69 \pm 1.219$ & $49.91 \pm 1.764$ & $55.84 \pm 1.790$ \\
\hline
\end{tabular}

Data are presented as $n$, least squares mean \pm SE or difference $(95 \% \mathrm{CI})$, unless otherwise stated. Repeated measures model with covariates of age, sex and baseline SGRQ total score. 

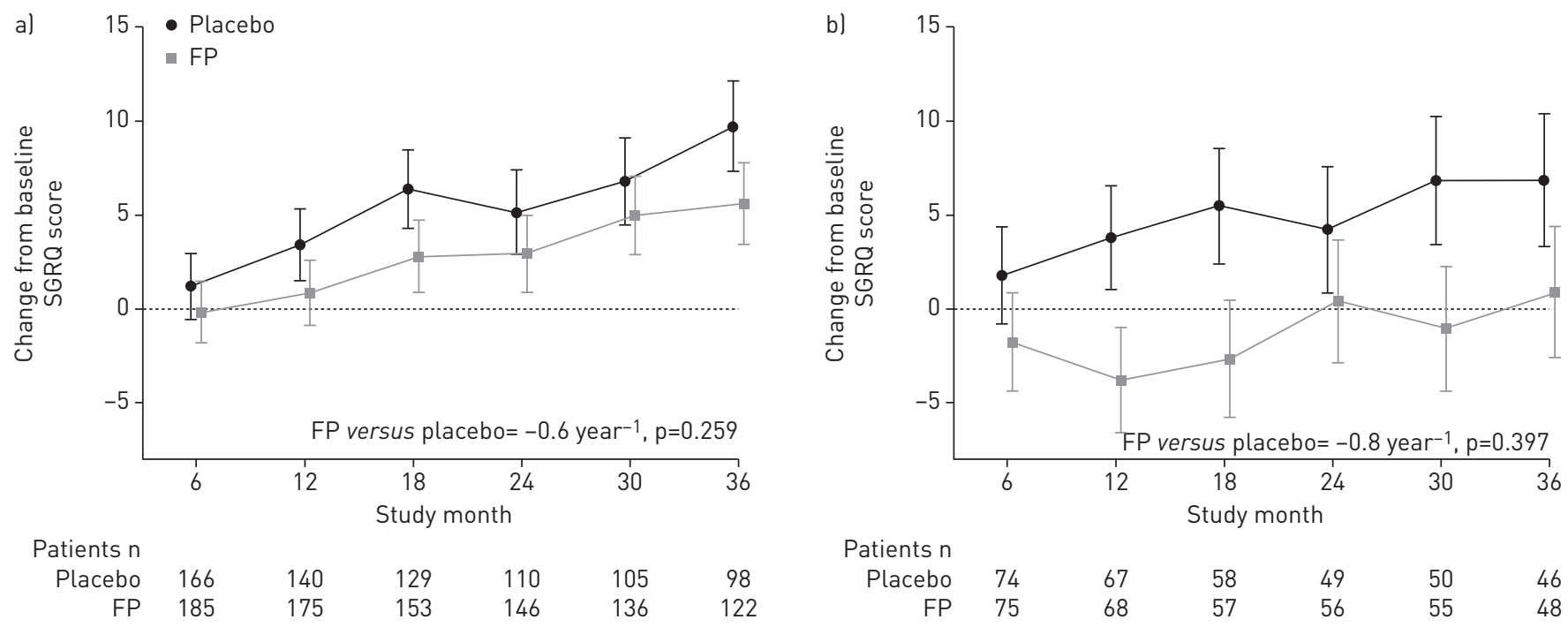

FIGURE 4 Adjusted least squares mean change (95\% CI) from baseline in St George's Respiratory Questionnaire (SGRQ) total score in patients receiving fluticasone propionate $500 \mu \mathrm{g}$ twice daily (FP) or placebo twice daily according to blood eosinophil level: a) $<2 \%$ and $b$ ) $\geqslant 2 \%$. The slope differences are derived from the random coefficients model.

eosinophil count than seen in more contemporary trials. Moreover, our patients were not selected on the basis of a prior exacerbation history, a variable highly predictive of subsequent events [26]. Information on prior exacerbation history in ISOLDE was not recorded, and thus it is possible that by chance there was an imbalance in the risk of an exacerbation between treatments in the high and low eosinophil groups.

We saw differences in the more immediate effects of fluticasone propionate in terms of a larger change in FEV1 and greater improvement in health status in the higher eosinophil group, which were sustained throughout the study. The change in FEV1 was seen in both groups and was similar to that noted recently when ICS treatment is withdrawn [27]. However, this was not related to the subsequent FEV1 decline and may represent a different process. The improvement in SGRQ score seen in both eosinophil groups with fluticasone propionate therapy is likely to reflect the impact on exacerbations. However, neither the subsequent change in health status nor the risk of study dropout was influenced by eosinophil level. We saw a greater likelihood of having a pneumonia reported in the low eosinophil subgroup given fluticasone propionate, a finding not replicated as yet in other studies $[16,17]$. Blood eosinophils did not change meaningfully over time with ICS treatment nor were they influenced by exacerbations prior to clinic visits, suggesting that eosinophil counts are stable, which increases their potential utility as a marker of treatment response to ICS.

The strengths of the current analysis include the long duration of the primary ISOLDE study (3 years), and the fact that eosinophil counts were recorded at screening and at the study start, and at intervals throughout the study. Limitations of our study include the inconclusive findings from the exacerbations analysis and the high rate of patient withdrawal from the primary ISOLDE study. However, despite the high withdrawal rate in ISOLDE, there did not seem to be a difference in withdrawal rate between those with eosinophils $<2 \%$ and $\geqslant 2 \%$ at baseline, and in the current analysis withdrawals were comparable between fluticasone propionate and placebo for both eosinophil groups. Our sample size was relatively small, reducing the robustness of this analysis, and was insufficient to investigate a range of eosinophil thresholds. Differences observed in small subsets of patients should also, therefore, be treated with caution. The study's age ( $>10$ years) may also have limited the extent to which it reflects modern-day treatment, standard-of-care and levels of COPD control. Finally, we currently lack a clear mechanistic explanation of how blood eosinophilia relates to airway inflammation in COPD and through what pathways the beneficial effect on disease progression is mediated. However, a study by Hospers et al. [28] provides support for our findings. In that study of cardiovascular mortality, higher eosinophil counts were associated with poorer lung function, as measured by FEV1 [28].

Taken together, our findings suggest that a baseline blood eosinophil count of $\geqslant 2 \%$ identifies a group of COPD patients who show slower rate of decline in FEV1 when treated with ICS. However, based on these findings we are unable to judge whether the results would be similar for treatment with ICS plus LABA. Prospective testing of this hypothesis is now warranted.

\section{Acknowledgements}

The authors would like to thank Dawn Midwinter (GSK, Uxbridge, UK) and Sandra Williams (Veramed, Twickenham, UK) for their support in data analysis for this paper. Editorial support in the form of development of the draft outline 
and manuscript first draft in consultation with the authors, editorial suggestions to draft versions of this paper, assembling tables and figures, collating author comments, initial copyediting, fact checking, referencing and graphic services was provided by Ian Grieve and Cheryl Wright at Gardiner-Caldwell Communications (Macclesfield, UK) and was funded by GSK.

\section{References}

1 Global Initiative for Chronic Obstructive Lung Disease (GOLD). Global Strategy for the Diagnosis, Management and Prevention of COPD. www.goldcopd.org/guidelines-global-strategy-for-diagnosis-management.html Date last accessed: June 19, 2015. Date last updated: January 2015.

2 Vestbo J, Edwards LD, Scanlon PD, et al. Changes in forced expiratory volume in 1 second over time in COPD. N Engl J Med 2011; 365: 1184-1192.

3 Calverley P, Pauwels R, Vestbo J, et al. Combined salmeterol and fluticasone in the treatment of chronic pulmonary disease: a randomised controlled trial. Lancet 2003; 361: 449-456.

4 Calverley PM, Anderson JA, Celli B, et al. Salmeterol and fluticasone propionate and survival in chronic obstructive pulmonary disease. N Engl J Med 2007; 356: 775-789.

5 Dransfield MT, Bourbeau J, Jones PW, et al. Once-daily inhaled fluticasone furoate and vilanterol versus vilanterol only for prevention of exacerbations of COPD: two replicate double-blind, parallel-group, randomised controlled trials. Lancet Respir Med 2013; 1: 210-223.

6 Calverley PM, Stockley RA, Seemungal TA, et al. Reported pneumonia in patients with COPD: findings from the INSPIRE study. Chest 2011; 139: 505-512.

7 Crim C, Calverley PM, Anderson JA, et al. Pneumonia risk in COPD patients receiving inhaled corticosteroids alone or in combination: TORCH study results. Eur Respir J 2009; 34: 641-647.

8 Kew KM, Seniukovich A. Inhaled steroids and risk of pneumonia for chronic obstructive pulmonary disease. Cochrane Database Syst Rev 2014; 3: CD010115.

9 Burge PS, Calverley PMA, Jones PW, et al. Randomised, double blind, placebo controlled study of fluticasone propionate in patients with moderate to severe chronic obstructive pulmonary disease: the ISOLDE trial. BMI 2000; 320: 1297-1303.

10 Siva R, Green RH, Brightling CE, et al. Eosinophilic airway inflammation and exacerbations of COPD: a randomised controlled trial. Eur Respir J 2007; 29: 906-913.

11 McDonald VM, Higgins I, Wood LG, et al. Multidimensional assessment and tailored interventions for COPD: respiratory utopia or common sense? Thorax 2013; 68: 691-694

12 Chanez P, Vignola AM, O'Shaughnessy T, et al. Corticosteroid reversibility in COPD is related to features of asthma. Am J Respir Crit Care Med 1997; 155: 1529-1534.

13 Brightling CE, Monteiro W, Ward R, et al. Sputum eosinophilia and short-term response to prednisolone in chronic obstructive pulmonary disease: a randomised controlled trial. Lancet 2000; 356: 1480-1485.

14 Bafadhel M, McKenna S, Terry S, et al. Blood eosinophils to direct corticosteroid treatment of exacerbations of chronic obstructive pulmonary disease: a randomized placebo-controlled trial. Am J Respir Crit Care Med 2012; 186: 48-55.

15 Pascoe S, Locantore N, Dransfield MT, et al. Blood eosinophil count as a biomarker of ICS effectiveness in reducing exacerbation rates in COPD. Eur Respir J 2014; 44: Suppl. 58, P2817.

16 Pascoe S, Locantore N, Dransfield MT, et al. Blood eosinophil counts, exacerbations and response to the addition of inhaled fluticasone furoate to vilanterol in patients with chronic obstructive pulmonary disease: a secondary analysis of data from two parallel randomised controlled trials. Lancet Respir Med 2015; 3: 435-442.

17 Siddiqui S, Guasconi A, Vestbo J, et al. Blood eosinophils: a biomarker of response to extrafine beclomethasone/ formoterol in chronic obstructive pulmonary disease. Am J Respir Crit Care Med 2015; 192: 523-525.

18 Hospers JJ, Schouten JP, Weiss ST, et al. Asthma attacks with eosinophilia predict mortality from chronic obstructive pulmonary disease in a general population sample. Am J Respir Crit Care Med 1999; 160: 1869-1874.

19 Jones PW, Quirk FH, Baveystock CM, et al. A selfcomplete measure of health status for chronic airflow limitation. The St George's respiratory questionnaire. Am Rev Respir Dis 1992; 145: 1321-1327.

20 Keene ON, Calverley PM, Jones PW, et al. Statistical analysis of exacerbation rates in COPD: TRISTAN and ISOLDE revisited. Eur Respir J 2008; 32: 17-24.

21 Vestbo J, Sorensen T, Lange P, et al. Long-term effect of inhaled budesonide in mild and moderate chronic obstructive pulmonary disease: a randomised controlled trial. Lancet 1999; 353: 1819-1823.

22 Pauwels RA, Löfdahl C-G, Laitinen LA, et al. Long-term treatment with inhaled budesonide in persons with mild chronic obstructive pulmonary disease who continue smoking. N Engl J Med 1999; 340: 1948-1953.

23 The Lung Health Study research Group. Effect of inhaled triamcinolone on the decline in pulmonary function in chronic obstructive pulmonary disease. N Engl J Med 2000; 343: 1902-1909.

24 Celli BR, Thomas NE, Anderson JA, et al. Effect of pharmacotherapy on rate of decline of lung function in chronic obstructive pulmonary disease: results from the TORCH study. Am J Respir Crit Care Med 2008; 178: 332-338.

25 Jarad NA, Wedzicha JA, Burge PS, et al. An observational study of inhaled corticosteroid withdrawal in stable chronic obstructive pulmonary disease. ISOLDE Study Group. Respir Med 1999; 93: 161-166.

26 Hurst JR, Vestbo J, Anzueto A, et al. Susceptibility to exacerbation in chronic obstructive pulmonary disease. N Engl J Med 2010; 363: 1128-1138.

27 Magnussen H, Disse B, Rodriguez-Roisin R, et al. Withdrawal of inhaled glucocorticoids and exacerbations of COPD. N Engl J Med 2014; 371: 1285-1294.

28 Hospers JJ, Rijcken B, Schouten JP, et al. Eosinophilia and positive skin tests predict cardiovascular mortality in a general population sample followed for 30 years. Am J Epidemiol 1999; 150: 482-491. 